\title{
Адсорбция аминокислот на углеродных наночастицах различных производителей
}

\author{
Измайлова Е.А., Бутырская Е.В., Нечаева Л.С., \\ Козлова И.В., Запрягаев С.А. \\ ФГБОУ ВО «Воронежский государственный университет», Воронеж
}

Поступила в редакцию 31.01.2017 г.

Исследованы изотермы адсорбции 1-аминокислот на углеродных наночастицах. Выявлена максимальная адсорбция 1-аминокислот на углеродных нанотрубках. Установлено, что изотермы адсорбции l-аминокислоты не имеют перегиба, имеют 1 плато, и, по классификации Брунауэра относятся к I типу изотерм адсорбции, следовательно, можно говорить о мономолекулярной сорбции. Предположительно, исследуемые аминокислоты адсорбируются конечными участками нанотрубок.

Ключевые слова: углеродные наночастицы, 1-минокислоты, адсорбция.

\section{Adsorption of amino acids on carbon nanoparticles of different manufacturers}

\author{
Izmajlova E.A., Butyrskaya E.V., Nechaeva L. S., \\ Kozlova I.V., Zapryagaev S.A. \\ Voronezh State University, Voronezh
}

\begin{abstract}
Carbonnanoparticles have rapidly become one of the most widely studied nanomaterials, primarily because their unique physicochemical properties and wide-rangingapplications in molecular electronics, optoelectronics, drug delivery, and chemical and biological sensors, end sorption technologies. With regard to biomedical applications of CNTs, the most important prerequisite is the development of methods to immobilize biomolecules on CNTs. The adsorption and functionalization of biological molecules on CNTs are common way to realize immobilization of biological molecules. So, the understanding of the interaction mechanism between CNTs and biological molecules is mandatory for safe using of CNTs in biological applications. Amino acids are an elementary unit for composing biomolecules and can also reflect the common chemical properties of complicated biomolecules. So, the interaction between CNTs and. amino acidsis very important for understanding the interaction mechanism between CNTs and biomolecules.

In this article, the adsorption isotherms ofl-amino acids (lysine, arginine) from aqueous solutions by carbon nanoparticles were constructed. It was found that arginine adsorption by fullerene C60 and CNT MKNanoP5000 is more effective than lysine adsorption. For the CNT MKNanoS1 and CNTs DEALTOM adsorption of the lysineis more efficient then arginine one. Adsorption isotherms were described by the equations of Langmuir and Freundlich.
\end{abstract}

Keywords: amino acid, carbon nanotubes, adsorption.

\section{Введение}

Углеродные наночастицы (УНЧ) принадлежат к числу перспективных наноматериалов и продолжают привлекать пристальное внимание исследователей многих стран мира. Наряду с фуллеренами, углеродные нанотрубки образуют новый 
класс углеродных наноматериалов, или углеродных каркасных структур со свойствами, которые значительно отличаются от других форм углерода, таких как графит и алмаз. Поскольку углеродные наночастицы открыты сравнительно недавно, сведения об их адсорбционных свойствах в литературе недостаточны, несистематизированы и неполны, что обуславливает актуальность данного исследования [1-3]. Цель настоящей работы состоит в исследовании адсорбции аминокислот на углеродных наночастицах различных производителей.

\section{Эксперимент}

В качестве сорбатов были выбраны 1-лизин и 1-аргинин, а в качестве сорбентов - фуллерен $\mathrm{C}_{60}$ (Санкт - Петербург), УНT DEALTOM (Москва), MKNanoS1, MKNanoP5000 (Канада). Для получения устойчивых суспензий углеродных наночастиц в водных растворах была использована их ультразвуковая обработка.

Построение изотерм проводили методом переменных концентраций в сочетании с объемным методом измерения адсорбции при $\mathrm{pH} \mathrm{5.5.} \mathrm{К} 0.01$ г УНЧ добавляли водные растворы аминокислот различных концентраций, так, что бы объем жидкости над сорбентом равнялся $20 \mathrm{~cm}^{3}$. Полученные суспензии обрабатывали ультразвуком, и оставляли в шейкере-инкубаторе при непрерывном перемешивании на 6 часов. В ходе исследования кинетики установлено, что максимальная величина адсорбции наблюдается через 19 часов контакта 1 - аргинина с углеродными наночастицамиMKNanoP5000, MKNanoS1 (Канада), DEALTOM (Москва), фуллерен $\mathrm{C}_{60}$ (Санкт - Петербург) и через 17 часов контакта 1 -лизина с УНЧ. Затем полученные суспензии центрифугировали. Концентрацию аминокислоты в супертанате определяли спектрофотометрически.

\section{Обсуждение результатов}

Изотермы адсорбции представлены на рисунках 1-4. Анализ изотерм показал, что: -адсорбция 1-лизина и 1-аргинина максимальна при использовании в качестве сорбента УНТ MKNanoP5000 (рис.1);

-дляУНT DEALTOMиMKNanoS1 адсорбция лизинаболее эффективна, чем аргинина (рис.2,3);

- для фуллерена C60 и УНT MKNanoP5000 адсорбция аргинина более эффективна, чем адсорбция лизина (рис. 1-4).

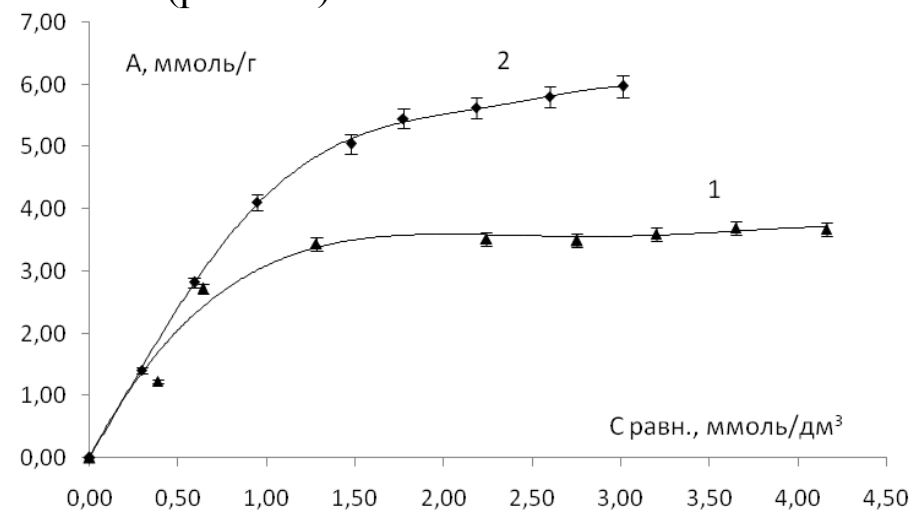

Рис. 1. Изотермы адсорбции 1- лизина(1) и 1-аргинина (2) на углеродных нанотрубках MK Nano P5000 


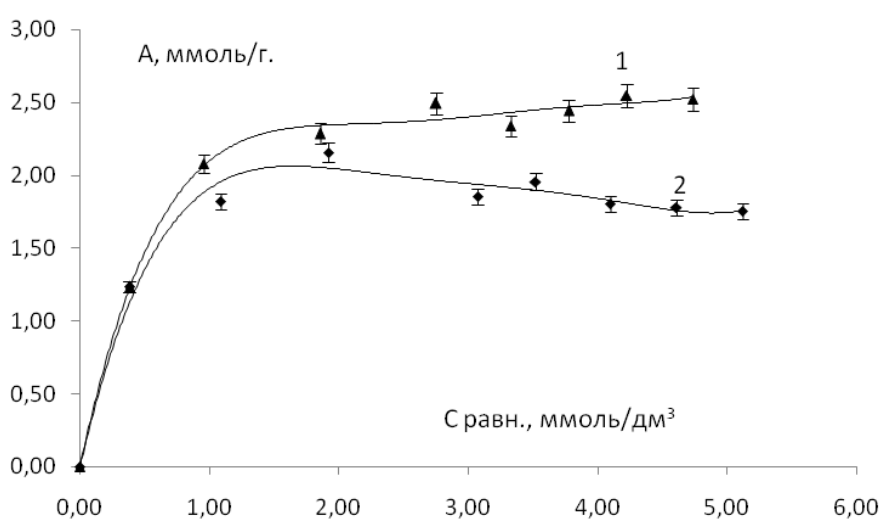

Рис. 2. Изотермы адсорбции 1-лизина(1) и 1-аргинина (2) на углеродных нанотрубках MK Nano S1

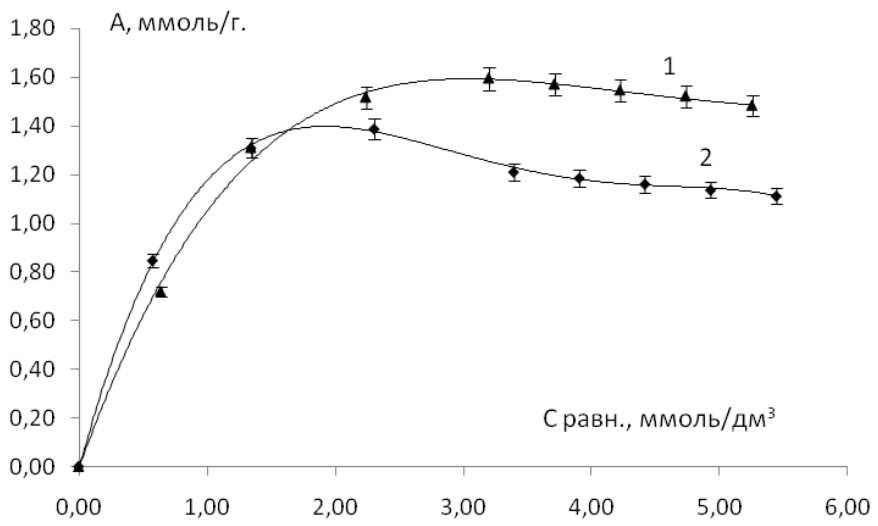

Рис. 3. Изотермы адсорбции 1-лизина(1) и 1-аргинина (2) на углеродных нанотрубках DEALTOM (Москва)

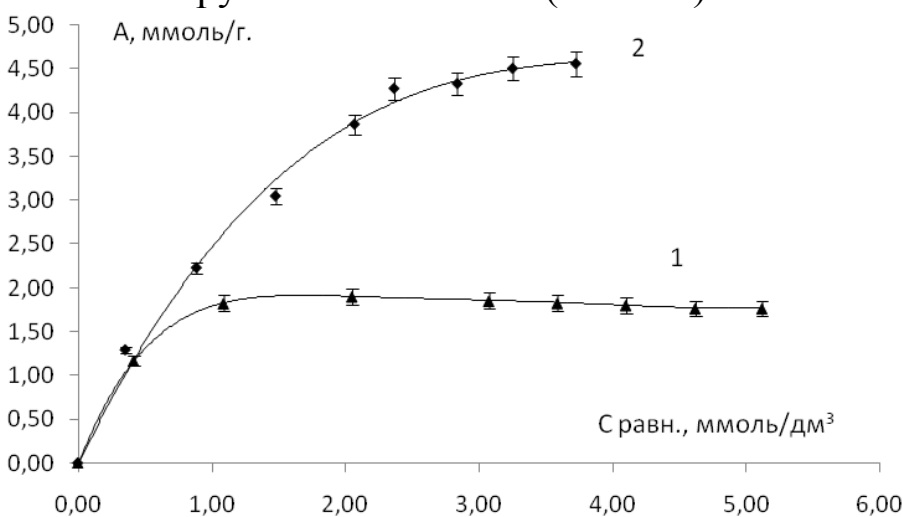

Рис. 4. Изотермы адсорбции 1-лизина(1) и 1-аргинина (2) на фуллерене $\mathrm{C}_{60}$ (Санкт - Петербург)

Из рис. 1-4 видно, что изотермы адсорбции 1-аргинина и 1-лизина имеют одно плато, и, по классификации Брунауэра, относятся к I типу изотерм адсорбции, следовательно, можно говорить о мономолекулярной сорбции.

Изотермы адсорбции 1-аргинина и 1-лизина количественно описаны уравнениями Ленгмюра и Фрейндлиха. По линеаризованным формам уравнений рассчитаны величины предельной адсорбции, констант и коэффициентов корреляции $\left(\mathrm{R}^{2}\right)$. Результаты приведены в табл. 1. 
Значения коэффициентов корреляции линеаризованных уравнений показывают, что адсорбция 1-аргинина и 1-лизина с большой вероятностью описывается теорией мономолекулярной адсорбции Ленгмюра.

Таблица 1. Параметры адсорбции 1-аргинина и 1-лизина углеродными нанотрубками, рассчитанные с использованием уравнений Ленгмюра и Фрейндлиха.

\begin{tabular}{|c|c|c|}
\hline \multirow{2}{*}{ Система } & \multicolumn{2}{|c|}{ Параметры } \\
\hline & изотерма Ленгмюра & изотерма Фрейндиха \\
\hline $\begin{array}{l}\text { 1-аргинин + УНТ Mknano } \\
\text { MWCNT P5000, Канада }\end{array}$ & $\begin{array}{c}\mathrm{A}_{\infty}=9.764 \text { ммоль } / \Gamma \\
\mathrm{K}_{\mathrm{L}=0.011 \mathrm{~cm}^{3} / \text { ммоль }} \\
\mathrm{R}^{2}=0.993\end{array}$ & $\begin{array}{c}\mathrm{K}_{\mathrm{F}}=3.565 \\
\left(\mathrm{~cm}^{31 / \mathrm{n}} \cdot \mathrm{M} \text { моль }\right. \\
\mathrm{n}=1.1 / \mathrm{n}) / \Gamma \\
\mathrm{R}^{2=} 0.921\end{array}$ \\
\hline $\begin{array}{l}\text { 1-лизин + УНT Mknano } \\
\text { MWCNT P5000, Канада }\end{array}$ & $\begin{array}{c}\mathrm{A}_{\infty}=5.291 \text { ммоль } / \Gamma \\
\mathrm{K}_{\mathrm{L}=0}=025 \mathrm{~cm}^{3} / \text { ммоль } \\
\mathrm{R}^{2}=0.990\end{array}$ & $\begin{array}{c}\mathrm{K}_{\mathrm{F}}=2.449 \\
\left(\mathrm{~cm}^{31 / \mathrm{n}} \cdot \mathrm{M} \mathrm{моль}^{1-1 / \mathrm{n}}\right) / \Gamma \\
\mathrm{n}=2.732 \\
\mathrm{R}^{2=} 0.825\end{array}$ \\
\hline $\begin{array}{l}\text { 1-аргинин + УНT Mknano } \\
\text { MWCNT S1, Канада }\end{array}$ & $\begin{array}{c}\mathrm{A}_{\infty}=2.012 \text { ммоль } / \Gamma \\
\mathrm{K}_{\mathrm{L}=0.065 \mathrm{~cm}^{3} / \text { ммоль }} \\
\mathrm{R}^{2}=0.987\end{array}$ & $\begin{array}{c}\mathrm{K}_{\mathrm{F}}=1.603 \\
\left(\mathrm{~cm}^{31 / \mathrm{n}} \cdot \mathrm{M} \text { моль }\right. \\
\mathrm{n}=8.445 \\
\mathrm{R}^{2=}=0.758\end{array}$ \\
\hline $\begin{array}{l}\text { 1-лизин + УНT Mknano } \\
\text { MWCNT S1, Канада }\end{array}$ & $\begin{array}{c}\mathrm{A}_{\infty}=2.849 \text { ммоль } / \Gamma \\
\mathrm{K}_{\mathrm{L}=0.046 \mathrm{~cm}^{3} / \text { ммоль }} \\
\mathrm{R}^{2}=0.995\end{array}$ & $\begin{array}{c}\mathrm{K}_{\mathrm{F}}=1.766 \\
\left(\mathrm{~cm}^{31 / \mathrm{n}} \cdot \mathrm{M} \mathrm{моль}^{1-1 / \mathrm{n}}\right) / \Gamma \\
\mathrm{n}=3.922 \\
\mathrm{R}^{2}=0.872\end{array}$ \\
\hline $\begin{array}{c}\text { 1-аргинин + УНT DEALTOM } \\
\text { (Москва) }\end{array}$ & $\begin{array}{c}\mathrm{A}_{\infty}=1.292 \text { ммоль } / \Gamma \\
\mathrm{K}_{\mathrm{L}=0.101 \mathrm{~cm}^{3} / \text { ммоль }} \\
\mathrm{R}^{2}=0.991\end{array}$ & $\begin{array}{c}\mathrm{K}_{\mathrm{F}}=1.067 \\
\left(\mathrm{~cm}^{3}{ }^{1 / \mathrm{n}} \cdot \mathrm{M} \text { моль } 1-1 / \mathrm{n}\right) / \mathrm{r} \\
\mathrm{n}=12.048 \\
\mathrm{R}^{2}=0.930 \\
\end{array}$ \\
\hline $\begin{array}{c}\text { 1-лизин + УНT DEALTOM } \\
\text { (Москва) }\end{array}$ & $\begin{array}{c}\mathrm{A}_{\infty}=2.037 \text { ммоль } / \Gamma \\
\mathrm{K}_{\mathrm{L}}=0.064 \mathrm{~cm}^{3} / \text { ммоль } \\
\mathrm{R}^{2}=0.923\end{array}$ & $\begin{array}{c}\mathrm{K}_{\mathrm{F}}=1.005 \\
\left(\mathrm{~cm}^{3}{ }^{1 / \mathrm{n}} \cdot \mathrm{M} \text { моль } 1-1 / \mathrm{n}\right) / \text { г } \\
\mathrm{n}=3.135 \\
\mathrm{R}^{2}=0.748\end{array}$ \\
\hline $\begin{array}{c}\text { 1-аргинин + фуллерен } \mathrm{C}_{60} \\
\text { (Санкт - Петербург) }\end{array}$ & $\begin{array}{c}\mathrm{A}_{\infty}=6.289 \text { ммоль } / \Gamma \\
\mathrm{K}_{\mathrm{L}=}=0.021 \mathrm{~cm}^{3} / \text { ммоль } \\
\mathrm{R}^{2}=0.990\end{array}$ & $\begin{array}{c}\mathrm{K}_{\mathrm{F}}=2.399 \\
\left(\mathrm{~cm}^{31 / \mathrm{n}} \cdot \mathrm{M} \text { моль } 1-1 / \mathrm{n}\right) / \Gamma \\
\mathrm{n}=1.776 \\
\mathrm{R}^{2}=0.881\end{array}$ \\
\hline $\begin{array}{c}\text { 1-лизин + фуллерен } \mathrm{C}_{60} \\
\text { (Санкт - Петербург) }\end{array}$ & $\begin{array}{c}\mathrm{A}_{\infty}=1.988 \text { ммоль } / \Gamma \\
\mathrm{K}_{\mathrm{L}=0.065 \mathrm{~cm}^{3} / \text { ммоль }} \\
\mathrm{R}^{2}=0.858\end{array}$ & $\begin{array}{c}\mathrm{K}_{\mathrm{F}}=1.528 \\
\left(\mathrm{~cm}^{3}{ }^{1 / \mathrm{n}} \cdot \mathrm{M} \text { моль } 1-1 / \mathrm{n}\right) / \mathrm{r} \\
\mathrm{n}=7.246 \\
\mathrm{R}^{2}=0.565\end{array}$ \\
\hline
\end{tabular}

\section{Заключение}

Построены изотермы адсорбции 1-аргинина и 1-лизина на фуллерене $\mathrm{C}_{60}$ и углеродных нанотрубкахMKNanoP5000, MKNanoS1, DEALTOM.Наибольшей адсорбционной способностью к указанным аминокислотам обладают УНT MKNanoP5000. Количественное описание построенных изотерм с помощью уравнений Ленгмюра и Фрейндлиха показывает, что адсорбция 1-аргинина и 1-лизина с большей вероятностью описывается теорией мономолекулярной адсорбции Ленгмюра.

Работа поддержана ФЦП «Исследования и разработки по приоритетным направлениям развития научно-технологического комплекса России 
на 2014-2020 годы», соглашение № 14.574.21.0112 от 21.10.2014, уникальный идентификатор проекта RFMEFI57414X0112.

\section{References}

1. Tersoff J., Phys. Rev. Lett., 1986, Vol. 56, pp. 632.

2. Che J., Cagin T., Goddard W.A., Nanotechnology, 1999, Vol. 10, pp. 263-268.

Бутырская Елена Васильевна - професcop, д.Х.н. кафедры аналитической химии Воронежского государственного университета, Воронеж

Измайлова Екатерина Анатольевна - аспирант кафедры аналитической химии Воронежского государственного университета, Воронеж

Нечаева Людмила Станиславовна - научный сотрудник кафедры аналитической химии Воронежского государственного университета, Воронеж

Козлова Илона Васильевна - магистр кафедры аналитической химии Воронежского государственного университета, Воронеж

Запрягаев Сергей Александрович - профессор кафедры цифровых технологий Воронежского государственного университета, Воронеж
3. Stewart J.J.P., J. Comp. Chem., 1989, Vol. 10, pp. 209-220.

4. Jorgensen W.L., Maxwell D.S., J. Am. Chem. Soc., 1996, Vol. 117, pp. 112-115.

Butyrskaya Elena V. - Doctor of chemical sciences, professor of department of analytical chemistry, chemical faculty, Voronezh State University, Voronezh

Izmajlova Ekaterina A. - Post-graduate Student, Department of Analytical Cemistry, Voronezh State University, Voronezh, e-mail: Ekaterina.izmajlova@mail.ru

Nechaeva Lyudmila S. - researcher at the Department of Analytical Chemistry, Voronezh State University, Voronezh.

Kozlova Ilona V.- Master of the Department of Analytical Chemistry, Voronezh State University, Voronezh

Zapryagaev Sergey A. - Professor of the Department of digital technology, Voronezh State University, Voronezh. 